\title{
Evaluating the Moral Intelligence of the Late Childhood (9-12) Years in Jordan: Al-Karak Governorate Case
}

\author{
Intisar Turki ALdarabah ${ }^{1}$, Reham Almohtadi ${ }^{1}$, Mustafa Jwaifell ${ }^{1} \&$ Raed Omar Salah ${ }^{1}$ \\ ${ }^{1}$ School of Education, Al-Hussein Bin Talal University, Ma'an, Jordan \\ Correspondence: Intisar Turki ALdarabah, School of Education, Al-Hussein Bin Talal University, P.O. Box (20), \\ Ma'an, Jordan. Tel: 96-279-810-8464. E-mail: Entesusm@yahoo.com
}

Received: December 10, 2014

Accepted: March 6, 2015

Online Published: April 24, 2015

doi:10.5539/jedp.v5n1p108

URL: http://dx.doi.org/10.5539/jedp.v5n1p108

\begin{abstract}
This research aims to revealing the moral intelligence level of the late childhood stage's children (9-12) years old in Al-Karak governorate in Jordan. In addition, revealing the differences according the variables (gender, family age, parent educational level, family size) on the level of the moral intelligence of the late childhood children's stage (9-12) years old in Al-Karak governorate in Jordan. Research population consists of the children whose ages range from (9-12) years old in Al-Karak governorate in Jordan, they are the children that pertain to the late childhood stage, which means the children who study in the third, fourth, fifth and sixth grades. After treating the data with the relevant statistical methods, the results showed that the level of moral intelligence was at a medium level of the late childhood children's stage (9-12) years old in Al-Karak governorate in Jordan. Moreover, the results indicated that there were no significant differences between the moral intelligence of the children according to (gender, family size, parent's educational level). On the other hand, the study showed there was a significant difference between the moral intelligence on the late childhood children's stage (9-12) years old in Al-Karak governorate in Jordan on the variable of parent's age.
\end{abstract}

Keywords: moral intelligence, late childhood, Al-Karak governorate

\section{Introduction}

Educational process on its core element the moral process since it deals with the human as a whole, bodily, spiritually and psychologically - to guarantee the best investment of his capabilities and abilities to the extent that makes him/her and those who surround him feel satisfaction and happiness. So, it is unsurprising that Johen Dewe has launched his saying: "education process and ethics are the same thing" (Hass, 1988). The researchers interest in studying the ethics generally and the moral development particularly came from ethics being the basic element of the society's presence and survival. No society is able to survive or continue without a set of rules, laws and regulations that control it and organize the relations between the individuals, and to be as the adopted standards in directing their behaviors and correcting their deviations (Gerjolj, 2008) from this point, it is possible to consider the Moral growth as one of the most important fields of research that has captured the educators interest, study, and investigation over the decades (Coles, 1997).

Today's children are living in the scientific and the technological explosion era, and what has accompanied this world of disturbances had led to imbalance in the values harmony, since the world has been invaded by the moral disintegration epidemic that has targeted the children directly, we hear a lot about the behavioral problems like deliquesce, crime and family's disintegration, this leads to the necessity to develop what called the Moral intelligence. The last decade has witnessed the emergence of the notable interest from the psychologists and education scientists' side to study the children's and the adolescences moral growth (Emmons, 2000), because of the obvious and urgent crisis in today society, which is a crisis that includes our children. Educators and parents and people in general all declared their worry about some of the frightful problems and catastrophes had been shown from the statistics suicides, the reason for that the children are more likely to commit the crimes because the criminals are becoming younger and younger (Kindlon \& Thompson, 2002). The educational studies show the spread of some problems among the children, including parents and teachers and incharge disrespect, and increased cruelty, misleading, fraud mistrust, lying and stealing (Coles, 1997). From this situation comes interest in the Moral side since it represents the building block in the personality structure and the lack in this side is 
responsible to a great limit for what we are suffering of today's moral, social and health problems. We are not exaggerating if we say that many of our current society's problems are moral problems in their core and represent the defect in the Moral development (Association of Supervision and Curriculum Development Panel on Moral Education, 1988). From this frame came the current research's idea, importance and problem.

\section{Theoretical Framework}

The moral intelligence concept has introduced through Borba (2001) works at the hand to explanation the ability of understand the right and the wrong actions, and the human to have moral believes, and works on them to be able to act honestly and appropriately.

This concept will help the child to be a good and honest human; this is the foundation of the coherent personality and to strong citizenship that the things we want to see in our children (Borba, 2001). Another definition if the Moral intelligence has emerged and identified by Gullikson (2004), which is what the parents provide as a model represents in the good conduct society if standards like respect, kindness and emotional warmth (Gullikson, 2004). Based on that (Borba) views that the moral intelligence, empathy, conscience, kindness, tolerance, and justice. The five dimensions make him in the right track and help him to behave morally. Following the illustration of the moral intelligence dimensions:

(1) Empathy: since the child becomes less selfish, more sympathetic and will understand that treating others kindly is the right thing that should be done, sympathy will make the child thinks of others needs and shows his interest, helps the needy, and stay close to those who got hear (Borba, 2001).

(2) Conscience: it is the strong inner voice that helps the child in determining what is right and what is wrong, and stay at the right path, and feels the conscience pain when he gets for from the right path, enables him to do the right things (Borba, 2002; Feldman, 2004).

(3) Kindness: it is the dimension that helps the child to re-direct his motives and thinking to act appropriately, and rarely makes the aimless decisions with results that might be danger (Borba, 2001).

(4) Tolerance: it is a strong Moral virtue that affects the child in dealing with the others kindly, understanding and encountering hate, violence, radicalism, respecting people based on their personality, this will help in the disappearance of hate \& violence (Borba, 2001; Gerjolj, 2008).

(5) Justice: it is a moral virtue that leads the children to treat others in unquotable way without bias and discrimination and fairness to be able to consider the rules and takes his role, listening openly to all parties before making his judgment (Goleman, 1995; Borba, 2001).

When the child achieves these five moral virtues, his moral intelligence considers on high level of intelligence. The child's capabilities in the moral intelligence widen with the available proper conditions for the moral growth (Borba, 2002), the child will have the ability to reach higher moral virtues such as self-control, humbleness, politeness, integration and sympathizing (Coles, 1988; Hass, 1997). The influencing factors on the moral intelligence are that it is obvious that in increasing number if children are in dangerous impasse because they did not acquire the moral intelligence, there are many of important social factors that monitor the moral personality, some of them are internal and others are external (Borba, 2001). Since the children are subject are these factors directly (Eisenheg \& Mussem, 1995).

2.1 The Role of the Family

One of the most important factors is the family that holds the responsibility of monitoring the children, so the family should hardly seeks to confirm the child's-self, developing his personality and providing him with the authentic values and ethics (Goleman, 1995). Also, the studies indicate that the mother's work, the parents' age, level of education, size of the family, and the number of the family members have important role in developing the moral intelligence (Zohar \& Marshall, 2001).

AL-Naser (2006) has indicated to a set of influencing factors in the family's role in the Moral; education, which is the following:

(1) Gender: studies had indicated to the presence of differences between the males and females in the Moral developmental process (Kindlon \& Thompson, 2002) since the females enjoy higher level of Moral intelligence compared to the males, this is because the mothers take longer time in raring and educating the females on the Moral virtues.

(2) Parents' age: Al-Qorsh (1986) study showed the effect with statistical significance of the parents' age variable on the Moral and social education, since it revealed that the younger parents tend to neglect more them the older parent, also the older parents tend to over-protection. 
(3) Parents' education level: the results of a study by Sears et al. (1969) showed that the more educated the mother the less they are severe with the children in the hygienic and eating table etiquettes and frequently use the discussion method as a training method.

(4) Another study conducted by Solt (1967) showed that mothers with high ideational level are more inclining to permissiveness in control than the less educated mothers. Al-Kahloot (2004) study found out the absence of relation between the adolescences moral intelligence level in the secondary stage and the mother's educational level, while (Sears, 1969) study has confirmed that the more the mothers are educated the less they are strict with the children. This explains that the mothers with high level of education are more inclined to permissiveness in controlling than the less educated mothers.

(5) Size of the family or the number of its members: studies showed that the effect of the family size has significant role. Stolz (1997) study has indicated to the presence of positive correlation between the number of the sons in the family and the mothers tendency to use the severe control and punishment in raring their sons, also the children's rejection, lack of protection and core about them (Mohammed, 2010).

Masharef (2009) study aimed to reveal the level of the moral intelligence and the level of the social responsibility of the students in the Islamic university in Gaza, also to reveal between them, in addition to the differences in each of them attribute to the variables (Gender, the faculty, the scholastic level, parents education level, the family's economic level, and the family size). The results showed differences with statistically significance in the Moral intelligence level between the males and females in favor of the females, also the presence of differences with statistically significance between the scientific and the literately faculties in favor of the literately faculties. While there were no differences with statistically significance in the Moral intelligence level of the university students attribute to the academic level of the variable the residency region, or the level of mother of father education level, or the variable the family size, or the variable the family economic level.

Adam (2002) pointed in his study to reveal the relation between the ethical growth and academic achievement, the family's social and economic level of the first secondary grade students in Damascus city's public schools, and the effect of gender variable on this relation. The results showed that there is a relation between the ethical growth and the variable the academic achievement and the socioeconomic level of the family. The results did not reach the presence of effect of the gender variable in this relation.

Shammari (2007) revealed that the correlation between the moral intelligence and the mutual social trust. Study sample reached (400) male and female students selected by the random stratified method from 8 colleges in Baghdad university. The researcher has built the Moral intelligence scale for the university students based on (Borba) theory in the Moral intelligence. The study reached that the university students enjoy the Moral intelligence, and the presence of a positive correlation with statistical significance between the mutual social trust and the Moral intelligence, in addition to the absence of difference in the Moral intelligence according to the variables, gender (males- females) and major scientific-humanitarian.

Al-obiadi and Al-ansari study (2011) aimed to reveal the Moral intelligence and its relation with the scholastic consistency of the sixth basic grade students in Baghdad city. Study sample consisted of (500) male and female students. The study measure has been applied and the results showed that the sixth basic grade students enjoy moral intelligence and the presence of positive correlation with statistically significance between the Moral intelligence and the scholastic consistence.

Qanawi (1987) conducted his study to compare between Egypt's and Bahrain's students in the moral development aimed to reveal the Moral thinking levels of the Egypt's and Bahrain's students in an attempt to know the effect of each country's culture on the Moral development. Study sample consisted of (80) children, half of them from Egypt's children and the other half from Al-Bahrain's children (Colberg). Moral maturity test has been applied (photo, A). The study reached the absence of differences with statistically significance between the children from the two countries since half of the children from both countries have the prevailing pre-traditional Moral thinking. Also, the study indicated to the absence of differences with statistically significance in the Moral development between the two genders of the Bahraini children and the Egypt's children, while there are differences with statistically significance in the Moral development between the two genders of each country in favor of the older children.

Walk and Taylor study (1991), they pointed to the family interaction and the moral development. They aimed to know the parents' role in developing and fostering their children's Moral thinking, and to know the extent of the effect of the parents Moral thinking, and to know the extent of the effect of the parents Moral thinking 
interaction on their sons when discussing the Moral issues and predating the child's behavior. Study sample reached (2014) individuals from (63) family represented by a father, a mother and a child, the children were selected from the first, fourth, seventh and tenth grades. The researchers had followed the experimental method in the study, and they reached that parents play the active and important role in their children's Moral development, also confirmed that the child's Moral development is predictable through the parental discussion and encouragement, formulating and inferring the children's ideas and opinions, and the high thinking level used in the dialogue, beside, the level of dialogue between the child and his peers that is known as being simple and ingenuous.

Al-Ansari (2011) conducted a study aimed to know the effect of parental treatment methods and their relation with the moral intelligence and the scholastic consistence of the sixth grade students, and to measure the Moral intelligence of the total research sample's individuals study balancing the Moral intelligence degrees of the study sample's individuals according to gender variable (males-females). The study revealed the necessity to confirm the parents' continuous use of the democratic style in dealing with their sons, to create the human who enjoys all of the positive traits when dealing with others, and for the family to be the basic financer in providing the Moral intelligence virtues to the sons.

\subsection{Statement of Study Problem}

The urgent need for more attention to moral intelligence has increased remarkably, because of the spread of behavioral modes among the students that characterized by (selfishness, greed, Jealousy, hate, robbery, cheating, stealing, violence and the drugs) all of these negative behaviors have motivated the inquiry and research in this problem that its effects will touch the whole society in terms of stability, order and save environment. The researchers see that the field Moral intelligence did not receive enough attention from the educators, families and the teachers. The problem stems from the undetermined roles and responsibilities of both the schools and the parents, and from the fact that Moral education process requires training and preparing the teachers to foster and motivate the Moral development of their students.

\subsection{Study Questions}

(1) What is the level of the Moral intelligence of the late childhood's children (9-12) years old in Al-Karak governorate in Jordan?

(2) Are there differences between the variables (gender, parent's age, parent's educational level, family size) on the level of the moral intelligence of the late childhood's children (9-12) years old in Al-Karak governorate in Jordan?

\subsection{Objectives of the Study}

(1) Revealing the Moral intelligence level of the late childhood stage's children (9-12) years old in Al-Karak governorate in Jordan.

(2) Revealing the differences between the variables (gender, parent's age, parent's educational level, family size) on the level of the Moral Intelligence of the late childhood children's stage (9-12) years old in Al-Karak governorate in Jordan?

\subsection{Significance of the Study}

Moral intelligence considers one of the new and important variables especially if it is studied for the childhood stage, since this variable has not been studied sufficiently and at a relevant degree for it. This research is one of the few researches (to the researchers' knowledge) that addresses the moral intelligence from this side, also the variables that the research is investigating are important and influencing variables on the individuals' personality which indicates to the importance of studying the research's variables through illustrating their theoretical and application side. So, this research considers a pioneering study in the childhood psychology field and represents a new qualitative addition to the childhood in Jordan and to the Jordanian library, in addition to that the Moral intelligence is an important factor in the individual's ability for self-control with the environment and the society, since it is as a monitor of his behaviors in order not to let go the self freely towards destruction or hostility and violating the society's laws.

\section{Method and Procedures}

The researchers have used a quantitative descriptive method, which is consisted of the independent variables:

(1) Gender: Female/male children aged 9-12 years.

(2) Age of mother and father of the children: 20 to 30, 31 to 40 and elder than 40. 
(3) Educational level of mother and father: School, Diploma and University degree.

(4) Family size: 1 to 5 and more than 5 children.

While the dependent variable is the moral intelligence measured by the instrument used in this study.

\subsection{Population of the Sample}

Research population consists of the children whose ages range from (9-12) years old in Al-Karak schools in Jordan, they are the children that pertain to the late childhood stage, which means the children who study in the third, fourth, fifth and sixth grades.

Table 1. Children distribution according to their gender and family size

\begin{tabular}{llll}
\hline The Targeted Group & Male & Female & Total \\
\hline Third Grade & 47 & 53 & 100 \\
Fourth Grade & 65 & 61 & 126 \\
Fifth Grade & 72 & 67 & 139 \\
Sixth Grade & 66 & 69 & 145 \\
Total & 250 & 250 & 500 \\
\hline
\end{tabular}

\subsection{Study Sample}

The sample has been collected by the stratified random method by the grade which included $30 \%$ of male and female students (500) from the research population (1627) taking into account that the sample represents all the scholastic levels, since the study sample unit is every child his age between (9-12) years from the late childhood stage. The reason for selecting the late childhood stage's students is because in this stage the child's Moral intelligence traits complete, and his Moral attitudes determined, he acquired and learned them from the older individuals and their growth complete. The child learns what is lawful and what the sin is, what is right and what is wrong, what is desirable and what is prohibited.

We notice at this stage that the child perceives concepts like: Honestly, Justice, and truth saying, and practice them as concepts, his for given's degree increase, and the behavior self-monitoring increase, here we find that the child has fixed attitude towards the right and wrong, and inclines to commitment to a general moral principle, and to what is prevailing the society.

So, we find that the child encounters every situation by applying the relevant and the prevailing rule in the society (Borba, 2001).

\subsection{Study Instrument: Moral Intelligence Scale (Mechile, 2001)}

The goal from this instrument is to know the level of the Moral intelligence level of the late childhood stag's students, this goal is measured through determining the measurement's fields since these fields were determined in the light of Michael Borba (2001) theory that depended on a theoretical frame, in which five dimensions in (86) clauses or items, the student is asked to answer them all through selecting one response, which is: always, often, sometime rarely, never, the following grades are taken accordingly $(1,2,3,4,5)$ for the positive items, and verse-versa for the negative items, Then the researchers have awarded the items and preparing the questionnaire in its preliminary form, since it included five dimensions for the moral intelligence which are, Empathy (24) items, the Conscience (28) items, Kindness (12) items, Tolerance (10) items, and Justice (10) items. The crucial score 3 used to determine the level of the moral intelligence, whether the responses fit often and always or rarely and never. In order to classified the level of the moral intelligence of the late childhood stage students in Al-Karak governorate the following criteria was used

(1) Less than 2.33 low

(2) 2.34 to 3.66 medium

(3) More than 3.67 high

\subsection{Instrument's Validity and Reliability}

Verifying the instrument's face validity the researchers have introduced the questionnaire to asset if specialized experts in the education field, psychology and kindergartens to confirm the items validity (face validity), the correctness of the linguistic clarity the extent of the items relevance to measure the moral intelligence of the late 
childhood stage's students, hence, to determine its validity. The needed modifications were made to the questionnaire in the light of the experts' opinions to prepare it in its final form, through omitting some of the clauses and replacing them by others, and modifying some words, then conducing a pioneer application for the measure the measure is applied to a random sample (30) male and female children, (15) males and (15) females students to make sure about the extent of the measure clauses clarity to the research's sample, in addition to know the time spent to answer the measure, it became clear that the measure's clauses were clear to the sample and time needed for the students' response to the measure's clauses has ranged between (15-20) minutes, with the mean $(5,17)$ minutes. Cronbach's Alpha used to test the reliability of the measurement tool, which was .88 for the 84 items that measures the moral intelligence; this showed the stability coefficient is relatively high.

\section{Findings and Results}

The researchers gathered the data collected out of the study sample, where the study sample distributed demographically as shown in Table 2 :

Table 2. Family and parents demographic distribution

\begin{tabular}{llll}
\hline Variable & & Father & Mother \\
\hline \multirow{3}{*}{ Age } & $20-30$ & 194 & 138 \\
& $31-40$ & 231 & 205 \\
& More than 40 & 75 & 157 \\
Education Level & School & 106 & 121 \\
& Diploma & 194 & 204 \\
Children Gender & University degree & 200 & 176 \\
Family Size & & Male & Female \\
& 1 to 5 children & 125 & 125 \\
\hline
\end{tabular}

Out of Table 2, it appears that 82 of the families the mothers elder than fathers, this finding related to the relative marriage as experienced at Al-Karak governorate to keep the family properties and inheritance within families, while fathers are more educated than mothers, which can be related to males responsibilities of establishing the family and having a appropriate work.

Data collected out of targeted sample, while the observable means shown in Table 3:

Table 3. Means and standard deviation of the targeted sample

\begin{tabular}{|c|c|c|c|c|c|c|}
\hline \multirow{2}{*}{ Variable } & & & \multicolumn{2}{|l|}{ Father } & \multicolumn{2}{|c|}{ Mother } \\
\hline & & & Mean & Std. Deviation & Mean & Std. Deviation \\
\hline \multirow{3}{*}{ Age } & $20-30$ & & 3.1699 & .34980 & 3.0857 & .38751 \\
\hline & $31-40$ & & 3.0786 & .37033 & 3.1687 & .28710 \\
\hline & More than 40 & & 3.1098 & .41716 & 3.0824 & .32928 \\
\hline \multirow{3}{*}{ Education Level } & School & & 3.0537 & .40286 & 3.0986 & .36181 \\
\hline & Diploma & & 3.1584 & .38984 & 3.1673 & .38754 \\
\hline & University degre & & 3.1147 & .33093 & 3.0760 & .35458 \\
\hline \multirow{4}{*}{ Family Size } & & & Mean & \multicolumn{3}{|c|}{ Std. Deviation } \\
\hline & 1 to 5 children & & \multicolumn{2}{|l|}{3.1003} & \multicolumn{2}{|c|}{.38275} \\
\hline & More than & 5 & 3.1395 & & \multicolumn{2}{|c|}{.35840} \\
\hline & & & \multicolumn{2}{|l|}{ Mean } & \multicolumn{2}{|c|}{ Std. Deviation } \\
\hline \multirow{2}{*}{ Gender } & Male & & 3.0964 & & \multicolumn{2}{|c|}{.35304} \\
\hline & Female & & 3.1410 & & \multicolumn{2}{|l|}{.38879} \\
\hline \multicolumn{3}{|l|}{ Total } & 3.1187 & & \multicolumn{2}{|l|}{.37165} \\
\hline
\end{tabular}




\subsection{Results of Question One}

To determine the level of the Moral Intelligence of the late childhood's children (9-12) years old in Al-Karak governorates in Jordan, responses of the targeted sample calculated to compare their means with the critical score of 3 that, which reflects the response of Sometimes at the measurement tool, where One-Sample T Test used to determine the Moral Intelligence, $\mathbf{t}_{.05,499}=3.1187$ showed significant difference $\mathbf{M}=3.1187$ above the crucial score 3. The responses of the children are at level rarely and never, this results show that the level of the Moral intelligence of the late childhood's children (9-12) years old in Al-Karak governorate in Jordan is medium.

4.2 Results of Question Two

Are there differences between the variables (parent's age, parent's educational level, family size) on the level of the moral intelligence of the late childhood's children (9-12) years old in Al-Karak governorate in Jordan?

Means and standard deviations are calculated to examine the differences between the study variables:

A-Gender Results: Independent-Samples T Test used to determine if there is difference between Male and Female children in Moral Intelligence, where $\mathbf{t}_{.05,498}=1.345$ is not significant $\alpha=.179$ which indicated that males with $\mathrm{M}=3.0964$ are equal to females $\mathrm{M}=3.1410$, thus the moral Intelligence are no differ significantly due to gender

B-Family Size Results: Independent-Samples T Test used to determine if there is difference between families who have 1 to 5 members and families who have more than 5 members in their children Moral Intelligence, where $\mathbf{t}_{.05}$, ${ }_{498}=1.176$ is not significant $\alpha=.240$ which indicated that $1-5$ members with $M=3.1003$ are equal to more than 5 members $\mathrm{M}=3.1395$, thus the Moral Intelligence are no differ between them.

C-Fathers Age Results: One way ANOVA used to examine the differences of Moral Intelligence according to fathers age. Table 4 shows the results of ANOVA:

Table 4. ANOVA analyses of fathers age influence on moral intelligence

\begin{tabular}{llllll}
\hline Source of Variance & Sum of Squares & df & Mean Square & F & Sig. \\
\hline Between Groups & .886 & 2 & .443 & 3.238 & .040 \\
Within Groups & 68.037 & 497 & .137 & & \\
Total & 68.923 & 499 & & & \\
\hline
\end{tabular}

ANOVA showed significant differences between the means of Moral Intelligence of the children according to their fathers age, where $F=3.238$ is statistically significance at $\alpha \leq .05$. It can be concluded that the level of Moral Intelligence of the late childhood's children (9-12) years old in Al-Karak schools in Jordan are differ according to the fathers age. Post hoc multiple comparison have been made by using Scheffe test, to determine the differences according to fathers age, where only fathers age between 20 to 30 years $\mathrm{MD}=.09133$ is significantly differ when the comparison made with the fathers age 31 to 40 years for the benefit of 20 to 30 years with $M=3.1699$, which can be conclude that Moral Intelligence of the late childhood's children (9-12) years old in Al-Karak governorate in Jordan are at medium level when fathers age between 20 to 30 years old.

$D-$ Mothers Age Results: One way ANOVA used to examine the differences of Moral Intelligence according to mothers age. Table 5 shows the results of ANOVA:

Table 5. ANOVA analyses of mothers age influence on moral intelligence

\begin{tabular}{llllll}
\hline Source of Variance & Sum of Squares & df & Mean Square & F & Sig. \\
\hline Between Groups & .869 & 2 & .434 & 3.173 & .043 \\
Within Groups & 68.054 & 497 & .137 & & \\
Total & 68.923 & 499 & & & \\
\hline
\end{tabular}

ANOVA showed significant differences between the means of moral intelligence of the children according to their mothers age, where $\mathrm{F}=3.173$ is statistically significance at $\alpha \leq .05$. It can be concluded that the level of Moral Intelligence of the late childhood's children (9-12) years old in Al-Karak governorate in Jordan are differ according to the mother's age. Post hoc multiple comparisons did not show statistical significance between the mean differences according to mothers age. 
E-Fathers Education Level Results: One way ANOVA used to examine the differences of moral intelligence according to fathers educational level. Table 6 shows the results of ANOVA:

Table 6. ANOVA analyses of fathers educational level on moral intelligence

\begin{tabular}{llllll}
\hline Source of Variance & Sum of Squares & df & Mean Square & F & Sig. \\
\hline Between Groups & .757 & 2 & .378 & 2.759 & .064 \\
Within Groups & 68.167 & 497 & .137 & & \\
Total & 68.923 & 499 & & & \\
\hline
\end{tabular}

ANOVA showed no significant differences between the means of Moral Intelligence of the children according to their fathers educational level, where $\mathrm{F}=2.759$ is not statistically significance at $\alpha \leq .05$. It can be concluded that the level of Moral Intelligence of the late childhood's children (9-12) years old in Al-Karak schools in Jordan are not differ according to the fathers educational level.

F-Mothers Education Level Results: One way ANOVA used to examine the differences of Moral Intelligence according to mothers educational level. Table 7 shows the results of ANOVA:

Table7. ANOVA analyses of mothers educational level on moral intelligence

\begin{tabular}{llllll}
\hline Source of Variance & Sum of Squares & df & Mean Square & F & Sig. \\
\hline Between Groups & .850 & 2 & .425 & 3.104 & .046 \\
Within Groups & 68.073 & 497 & .137 & & \\
Total & 68.923 & 499 & & & \\
\hline
\end{tabular}

ANOVA showed significant differences between the means of Moral Intelligence of the children according to their mothers age, where $\mathrm{F}=3.104$ is statistically significance at $\alpha \leq .05$. It can be concluded that the level of Moral Intelligence of the late childhood's children (9-12) years old in Al-Karak governorate in Jordan are differ according to the mothers educational level. Post hoc multiple comparisons did not show statistical significance between the mean differences according to mothers age.

\section{Discussion and Conclusion}

\subsection{To Answer the First Question}

The first research question addresses the level of moral intelligence of the late childhood (9-12) years old in Al-Karak governorate in Jordan. The level of moral intelligence was presented by a mean score on a 5-point Likert scale. The finding showed that the level is at a 3, this score indicates that the level of moral intelligence is at a medium level. This result is in congruence with findings of Qanawi (1987), who found the level of moral intelligence at medium level. There are several possible explanations for the above findings; one of the most likely explanations is that children at the late childhood not complete moral intelligence. Moreover, there alternative mothers who practice similar styles in the social parental with the children, whether males or females, based on the mentoring and raring style adopted by the village, and since the vast majority of the sample was concentrated on the villages, this means that the village has the constraints to impose on the children, and some of the traditional virtues exerted the focus on the masculinity and rigidity, violence and-forgiving, and feeling about the others to be the man of the future that leads to killing the permissiveness aspects, goodness and empathy, conscious, self-control and kindness, since the ethical intelligence aspects consider un-accepted in most families living in the village, from their view this produces a man with week and fragile personality that does not fit with the future masculinity function, this will confuse the childe more the youth regarding the contradiction in the ethical behavior, and here the child faces the difficulty in distinguishing between the situations, since it is difficult for the child to comprehend the precise differences between some of the situations that include some of the shared elements (Nasser, 2011). In this situation the child falls in the struggle with the social pressures, since some of the principles the group to which the child belongs appreciates might consider irrelevant to another group, when the child learns at home not to fight with others then he sees the peers group considers him cowered for that, he will be disturbed and confused in the choice issue. So, many families need training awareness program to develop the children's ethical intelligence dimension. On the other side, the 
researcher explains the result by kind of education introduced to the children at this stage since the mistakes the children fall in and punished for are without guiding them to what they should do.

\subsection{To Answer Question Two}

This section answer question two as follows:

\subsubsection{Gender}

The findings of this study indicated that there is no significant difference between the moral intelligence and gender. The analysis indicates that it does not mean if child meal or female, it means has high or low level moral intelligence. Thus, the gender is not a reliable indicator for the level of moral intelligence. The finding is similar with what Adam (2002), and Shamari (2007) found, they indicated that were no significant difference between the gender and moral intelligence. On the hand, the findings of this research contradicted with what Masharef (2009), Kindlon and Thompson (2002), Mohammad (1997) found the differences in favor of the females, also Al-Kahloot study the differences in favor of the females, also Al-Kahloot study (2004) also the differences in favor of the females. The possible reason to explain that may be the moral intelligence is not unit-dimensional, this means that there are rather a multi-dimensional, this means that there are dimensions in the moral intelligence that fit with male's nature and his psychological formation, and other dimensions fit with the females' nature. The researcher has found out that the males are more occupied with the general ethical issues and more able to be patient, more experience, and respect the law more and more persistent, while the females incline more to good treatment, more discipline in studying, more sensitive to empathy, feeling of fear, and regret, and self-blaming, because the female more committed to the ethical values, traditions and norm, also they are more in flounced by the religion and attracting to it and committed to them.

\subsubsection{Family Size}

The finding of the study revealed that there is no significant difference in the moral intelligence based on the family size. $\mathrm{T}$ Test used to determine if there is difference between families who have 1 to 5 members and families who have more than 5 members in their children moral intelligence, where $\mathbf{t}{ }_{.05,498}=1.176$ is not significant $\alpha=.240$ which indicated that $1-5$ members with $M=33.1003$ are equal to more than 5 members $\mathrm{M}=3.1395$, thus the Moral Intelligence are no differ between them. This result concurs with Masharef (2009), who found that there was no significant difference between the moral intelligence and family size. However, this result differs from the results of many with Stolz (1997), who found the presence of positive link between the family size and their moral maturity. The reason behind the above mentioned are related to the family size variable of the Jordanian family interest regardless of its size in the ethical parent raring of their sons. The Jordanian families are conservative and consider the Islamic and Arabic values and customs, and try to implant them in their sons. Also the intervention of the other institutions in this process that is un-separable from the family role like the school, the mosque, peers' group and the media. So all these institutions contribute to the ethical education process, and contribute to raise the students' Moral intelligence level.

\subsubsection{Mother's Level of Education}

ANOVA showed no significant differences between the means of moral intelligence of the children according to their fathers and mother educational level. This finding is supported by Masharef (2009), who indicated that there is no significant difference between the moral intelligence and the mother and father educational level. The explanation for this result due to the technological revolution, educational level is not important factor in determining the level of moral development of the child. Today, mothers have a great deal of knowledge about the methods of child-rearing. So, if the mothers are educated or uneducated are the leads to the same results. In conclusion, Moms are keen to provide their children a good upbringing in the methods by creates a child has the right moral growth.

\subsubsection{Family Age}

$\mathrm{T}$ Test used to determine if there is difference between families who have 1 to 5 members and families who have more than 5 members in their children moral intelligence, where $\mathbf{t}_{.05,498}=1.176$ is not significant $\alpha=.240$ which indicated that $1-5$ members with $\mathrm{M}=33.1003$ are equal to more than 5 members $\mathrm{M}=3.1395$, thus the moral intelligence are no differ between them. Also the findings indicated there is significant difference between the moral intelligence and the parent age. First, one way ANOVA used to examine the differences of moral intelligence according to fathers age. Fathers age between 20 to 30 years $\mathrm{MD}=.09133$ is significantly differ when the comparison made with the fathers age 31 to 40 years for the benefit of 20 to 30 years with $M=3.1699$, which can be conclude that moral intelligence of the late childhood's children (9-12) years old in Al-Karak governorate 
in Jordan are at medium level when fathers age between 20 to 30 years old. In addition, the analysis showed there is significant difference between the moral intelligence and the mother's age. The possible explanation behind this result because the fathers who studied till the secondary stage they have received little portion of the education, then it is believed that after the preparatory stage they move $\mathrm{d}$ to the work in the market or to the different professions, so they hold the responsibility at early age, this is what they transform to their sons later on. They have worked to encourage their sons to participate in holding the responsibility towards the family, and to interact with the society, this is what has been shown in their ethical intelligence. Also it is believed that most of them have the deficit in the social raring process of their sons and implanting the ethical intelligence concepts in them.

Regarding the mothers who have the university education: they care and interest in their sons that could reach the over protection that determines to the sons the times to go out, their interaction and engagement with the others mostly, the mothers with the university education level care about providing the climate for their sons that is limited time to go out with the friends. While the mothers with the primary education mostly marry at early age, they give birth to greater number of the sons, so they have less interest and protection to the sons that will enable the sons more time to go outside, more permissiveness to go out, engage, and participate in the different national and social activities. This issue provides the sons of the mothers with the primary education the greater opportunity to understand the social relation, and to be exposed to different experiences through their interaction and participation in the social activities understanding and practicing the rights and duties, so this explains their attainment of higher level of the social responsibility.

\section{References}

Al-Kahloot, E. H. (2004). A study of certain emotional and social variables and their relationship with the level of moral maturity to adolescents in the provinces of Gaza (Unpublished master's thesis). Faculty of Education, Department of Psychology, Al-Azhar University - Gaza.

Al-obiadi, A., \& Al-ansari, S. A. (20011). Moral Intelligence and its Relationship with Academic Adjustment for Sixth Year Primary School Pupils. Psychology Journal, 31.

Association of Supervision and Curriculum Development Panel on Moral Education. (1988). Moral education in the life of the school. Educational Leadership, 45(8), 4-8.

Borba, M. (2000). Parents Do make A difference. San Francisco, Jessy-Bass.

Borba, M. (2001). Building Moral Intelligence, The Seven Essential Virtues that Teach Kids to Do the Right Think. San Francisco, Jossey Bass.

Borba, M. (2002). Building Moral Intelligence, the Seven Virtues That Teach Kids to Do the Right Thing. Awiley Impaint, Jessey-Bass.

Coles, R. (1997). The moral intelligence of children: How to raise a moral child. New York: NAL/Dutton.

Eisenherg, N., \& Mussen, P. (1995). The roots of prosaically behavior in children. New York, Cambridge University.

Feldman, S. P. (2004). The Professional Conscience: A Psychoanalytic Study of Moral Character in Tolstoy's The Death of Ivan Ilych. Journal of Business Ethics, 49. http://dx.doi.org/10.1023/ B:BUSI.0000021052.57865.7b

Gardner, H. (2003). Multiple intelligences after twenty years. U.S.A, American Educational Research Association.

Gardner, H. (2004). Audiences for the theory of multiple intelligences. Theory College Record, 106(1), 212-220. http://dx.doi.org/10.1111/j.1467-9620.2004.00329.x

Gerjolj, S. (2008). The Relevance of Moral Intelligence in Educational Processes. Journal of Contemporary Research in Business, 8(3).

Goleman, D. (1995). Emotional intelligence. New York : Bantam.

Goodlad, J., Soder, R., \& Sirotnik, K. (Eds.). (1990). The moral dimensions of teaching. San Francisco: Jossey-Bass.

Gullickson, T. (2004). The Moral Intelligence of Children, How to Raise a Moral Child. New York, Bantam Books .

Hass, A. (1998). Doing the right thing: Cultivating your moral intelligence. New York: Hardcover. 
Kindlon, D., \& Thompson, M. (2002). Raising Can Protecting the Moral Life of Children. New York, Ballantine.

Lennick, D., \& Kiel, F. (2011, March). Moral Intelligence Enhancing Paper. Paper presented at the annual meeting of the Michigan Academy of Sciences, Arts and Letters Wayne State University, Detroit, MI, New York, Bantam Books.

Mohammed, R. (2010). The evolution of moral intelligence in adolescents. Retrieved December 10, 2014, from http://www.wahdai

Musharraf, M. M. (2009). Moral reasoning and its relationship to social responsibility and some Variables at the Islamic University of Gaza students (Unpublished master's thesis). Gaza University. Retrieved from http://library.iugaza.edu.ps/thesis/87112.pd

Nasser, A. (2009). The effectiveness of the educational program-Learning in the development of Moral intelligence in children Mistreated (Unpublished doctoral dissertation). University of Jordan, Amman, Jordan.

Qanawi, H. M. (1987). Comparative study between children in Egypt, Bahrain, congenital growth. Educational Studies magazine, 2(6), 67-109.

Shammari, A. (2007). The moral intelligence and its relationship to social trust Mutual (Unpublished master's thesis). Faculty of Arts, University of Baghdad.

Zohar, D., \& Marshall, I. (2001). Spiritual intelligence. The ultimate intelligence London Bloomsbury.

\section{Copyrights}

Copyright for this article is retained by the author(s), with first publication rights granted to the journal.

This is an open-access article distributed under the terms and conditions of the Creative Commons Attribution license (http://creativecommons.org/licenses/by/3.0/). 